\title{
Disease phenotype and diagnostic delay in Saudi patients with primary Sjögren's syndrome
}

\author{
An exploratory cross-sectional study
}

Mohammed A. Omair, MD, Bashaer S. AlQahtani, PhD, Esam H. AlHamad, MD, Yusra A. Tashkandy, PhD,

Nashwa S. Othman, MSc, Khalid A. AlShahrani, MD, Muthurajan P. Paramasivam, DTCD, Fahidah AlEnzi, MD,

Rabih Halwani, PhD, Maha H. Daghestani, PhD.

\section{ABSTRACT}

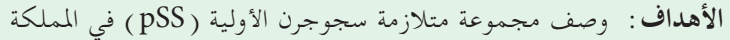

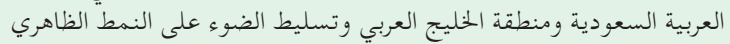

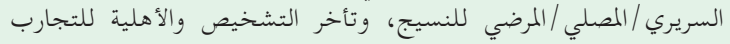

$$
\begin{aligned}
& \text { السريرية المستقبلية . المتلية } \\
& \text { المنهجية : أجريت دراسة مقطعية خلال الفترة بين أكتوبر 2018م ومائ الإيو }
\end{aligned}
$$

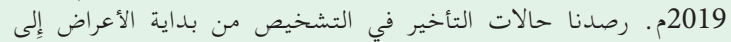

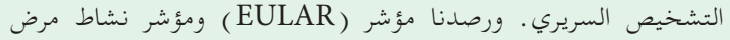

$$
\begin{aligned}
& \text { متلازمة سجوجرن (ESSDAI ) ومؤشر (ESSPRI (ESLAR) } \\
& \text { النتائج : اشتملت الدراسة على } 41 \text { مريضا في الدراسة. كان جنس الإناث }
\end{aligned}
$$

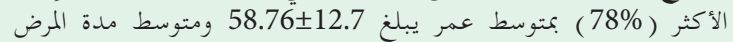

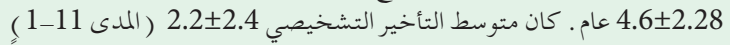

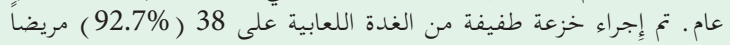

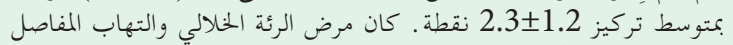

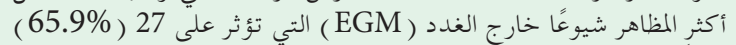

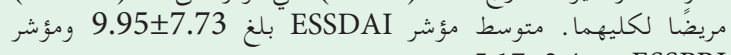

$$
\begin{aligned}
& \text { 5ان ESSPRI }
\end{aligned}
$$

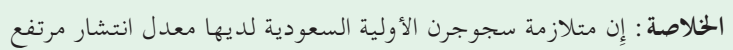

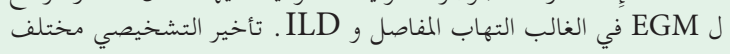

$$
\text { في دراستنا. }
$$

Objectives: To describe primary Sjögren's syndrome (pSS) cohort in Saudi Arabiain view in of clinical/ serological/histopathological phentotype, and, diagnostic delay.

Methods: A cross-sectional study conducted between October 2018 and May 2019. Diagnostic delay was calculated from symptoms onset to clinical diagnosis. The European League Against Rheumatism (EULAR) Sjögren's Syndrome Disease Activity Index (ESSDAI) and EULAR Sjogren's Syndrome Patient Reported Index (ESSPRI) were calculated.

Results: Forty-one patients were included in the study. There were predominantly females (78\%) with a mean $( \pm S D)$ age of $58.76 \pm 12.7$ and disease duration of $4.6 \pm 2.28$ years. The mean diagnostic delay was $2.2 \pm 2.4$ (range 1-11) years. Minor salivary gland biopsy was performed on 38 (92.7\%) patients with a mean focus score of $2.3 \pm 1.2$ points. Interstitial lung disease and arthritis were the most common extra-glandular manifestations (EGM) affecting 27 (65.9\%) patients for both. The mean ESSDAI was $9.95 \pm 7.73$ and ESSPRI was $5.17 \pm 2.4$.

Conclusion: Saudi primary Sjogren's syndrome patients have a high prevalence of EGM predominantly arthritis and ILD. The diagnostic delay is variable in our cohort.

Keywords: Sjögren's syndrome, disease phenotype, diagnosis, Saudi, primary

Saudi Med J 2021; Vol. 42 (4): 405-410 doi: 10.15537/smj.2021.42.4.20200767

From the Rheumatology Division (Omair), Pulmonary Division (AlHamad, Paramasivam) Department of Medicine, from the Department of Zoology (AlQahtani, Daghestani), College of Medicine, from the Department of Statistics and Operations Research, College of Sciences (Tashkandy), Central Laboratory (Othman), King Saud University; from the Rheumatology Division, Department of Medicine (AlShahrani), Diriyah General Hospital, Ministry of Health; from the Department of Clinical Science, College of Medicine (AlEnzi), Princess Nourah bint Abdulrahman University, Riyadh, Kingdom of Saudi Arabia; and from the Department of Clinical Sciences, College of Medicine (Halwani), Sharjah Institute for Medical Research, University of Sharjah, Sharjah, United Arab Emirates.

Received 27th November 2020. Accepted 22nd February 2021.

Address correspondence and reprint request to: $D r$. Mohammed A. Omair, Rheumatology Division, Department of Medicine, College of Medicine, King Saud University, Riyadh, Kingdom of Saudi Arabia. E-mail:momair@ksu.edu.sa

ORCID ID: http://orcid.org/0000-0002-9373-5473 
S jögren's syndrome is a chronic autoimmune disease characterized by impaired functioning of the exocrine glands due to lymphocytic infiltration and damage. ${ }^{1}$ Primary Sjögren's syndrome (pSS) is diagnosed in the absence of other connective tissue disease whereas secondary Sjögren's syndrome is diagnosed in patients with an underlying connective tissue disorder. Primary Sjögren's syndrome has been associated with a spectrum of extra-glandular manifestations, including inflammatory arthritis, Raynaud's phenomenon, cutaneous vasculitis, interstitial lung disease, interstitial nephritis, peripheral/central nervous system lesions and cytopenia. ${ }^{1-3}$ These systemic manifestations occur in a majority of patients and may cause significant organ damage, leading to increased morbidity and mortality. ${ }^{4,5}$ Ethnicity influences pSS phenotype as shown by the Big Data Sjögren Project Consortium an international multicenter registry that includes 20 centers from 5 continents. ${ }^{6}$ Brito-Zeron et al $^{7}$ reported significant phenotypic differences between ethnic groups. Hispanic and Caucasian individuals had a higher frequency of dryness symptoms and abnormal salivary gland biopsy findings. The age of diagnosis was 7 years earlier in Black/African Americans than in Caucasians. Disease activity and the predominance or frequency of extraglandular manifestations were significantly influenced by ethnic background. Differences were also seen in the autoantibody profile. ${ }^{7}$ There was a small representation of Arab ethnicity via patients recruited from Egypt. ${ }^{6}$ No study has evaluated pSS in the Arabian Gulf region in terms of diagnostic delay, disease characteristics, serological and histopathological findings. The aim of this study was to describe the first pSS cohort in Saudi Arabia and the Arabian Gulf region in view of clinical/ serological features and their eligibility into clinical trials.

Methods. This single-center, cross-sectional study describes the clinical stage of a comprehensive research project to elucidate the clinical characteristics, cytokine profile, and genetic profile of patients with pSS in

Disclosure. Authors have no conflict of interests, and the work was not supported or funded by any drug company. This study was funded by the Deanship of Scientific Research at Princess Nourah bint Abdulrahman University through the Research Funding Program (Grant No. FRP1441-4). The funding body did not have any influence on the study design, conduct of study, data analysis, or manuscript preparation.
Saudi Arabia from October 2018 and May 2019. The study participants were recruited from patients with pSS attending the rheumatology and pulmonary clinics at King Saud University, Riyahd, Saudi Arabia. Patients aged $\geq 18$ years with a diagnosis of pSS based on the American College of Rheumatology/EULAR classification criteria ${ }^{8}$ were invited to participate in the study. All patients were of Arab ethnicity.

The exclusion criteria included a confirmed diagnosis of malignancy, a major psychiatric disorder, and presence of end organ failure. The clinical characteristics, medications, laboratory investigations, and autoimmune profile were collected from patients' charts. Patients with grouped as patients identified in the ILD and rheumatology clinics. Diagnostic delay was calculated by patient interview and their recall of the onset of symptoms and date of diagnosis. A patient global assessment, a physician global assessment, and the clinical components of the ESSPRI were completed during clinic visits. The ESSPRI components were calculated individually and as a single factor composed of the mean of the 3 components (pain, fatigue, and dryness). ${ }^{9-11}$ Data on fatigue were already published in another report. ${ }^{12}$

The ESSDAI was calculated based on the score for 12 domains. ${ }^{9-11}$ The number of foci were calculated from minor salivary gland biopsies when available.

Convenience sampling of consecutive patients was used to reduce selection bias. The work is reported in accordance with the STROBE guidelines. ${ }^{13}$

The study was approved by the Institutional Research Board (IRB) at the College of Medicine, King Saud University (E-18-3206) and the IRB at Princess Nourah bint Abdulrahman University (19-0100). All procedures were performed in compliance with ethical standards and according to the Declaration of Helsinki. All patients signed an informed consent form prior to study enrolment.

Statistical analysis. The demographics and disease characteristics are summarized as descriptive statistics. The data were computed for discrete variables, including minimum and maximum values, means, standard deviations, proportions, and frequencies as appropriate. Parametric and non-parametric tests were used to compare disease subgroups based on the type of variable analyzed. All statistical analyses were performed using Statistical Package for Social Sciences software version 18.0 (IBM Corp., Armonk, NY, USA).

Results. Forty-one patients who fulfilled the study criteria between October 2018 and May 2019 were included in the final analysis. The patients were 
predominantly female $(\mathrm{n}=32,78 \%)$ with a mean age (and standard deviation) of $58.76 \pm 12.7$ years and a disease duration of $4.6 \pm 2.28$ years. The mean diagnostic delay was 2.2 \pm 2.4 (range 1-11) years. Patient identified in the pulmonary clinic had older age at diagnosis $(46.9 \pm 10.9$ versus $59 \pm 12.9 ; p<0.001)$ but shorter disease duration $(6 \pm 2.5$ versus $3.9 \pm 1.8 ; p=0.003)$. The mean ESSDAI scores were 9.95 \pm 7.73 and ESSPRI 5.17 \pm 2.4 . Seven patients had ESSDAI and 3 had ESSPRI scores of 0 . The main driver of ESSDAI score was pulmonary involvement. The mean respective patient global assessment scores were $5.2 \pm 2.37$ and physician global assessment $4.46 \pm 2.06$.

Anti-nuclear antibody was positive in $32(78 \%)$, rheumatoid factor in $10(24.4 \%)$, Sjogren's syndrome A antibody (SSA) 19 (46.3\%), and Sjogren's syndrome B antibody (SSB) in 12 patients (29.3\%). Patients identified in the rheumatology clinic had a higher risk to have a positive SSA ( $86 \%$ versus $26 \%$; $p<0.001)$. All patients identified in the pulmonary clinic had extraglandular manifestations (EGM) in the form of ILD with or without pulmonary hypertension compared to $64 \%$ in patients identified in the rheumatology clinic $(p=0.001)$ (Table 1). Serum cryoglobulins were not routinely assessed at baseline. A master table of all cases is illustrated in Table 2.

Minor salivary gland biopsy was performed in 38 (92.7\%) patients, with one biopsy being inconclusive and positive findings in 24 patients $(63.2 \%)$. The mean focus score was $2.3 \pm 1.2$ (Figure 1).

Sicca was the presenting symptom in 35 patients (85.4\%). Thirty-six $(87.8 \%)$ had one or more extraglandular manifestations. Pulmonary and articular involvement were the most common extra-glandular manifestations, with each affecting 27 (65.9\%) patients, followed by pulmonary hypertension, hematological, cutaneous, and peripheral nervous system involvement, renal dysfunction, thrombotic events, and central nervous system involvement (Figure 2). No patient had cryoglobulinemic vasculitis. No patient had developed lymphoma or any other type of malignancy at the most recent follow-up.

Discussion. The current study evaluates the clinical, serological and histopathological characteristics of patients with pSS in Saudi Arabia and the Middle East. We also have shown that patients identified by the pulmonologist in the Interstitial Lung Disease (ILD)

Table 1 - Demographics characteristics of patients included in this study.

\begin{tabular}{|c|c|c|c|c|}
\hline Demographics & $\mathrm{n}=41$ & $\begin{array}{l}\text { Rheumatology } \\
\text { clinic }\end{array}$ & Pulmonary clinic & $P$-value \\
\hline Female gender $(\%)$ & $32(78)$ & $13(93)$ & $19(70)$ & 0.099 \\
\hline Age at diagnosis (years) & $54.8 \pm 13.4$ & $46.9 \pm 10.9$ & $59 \pm 12.9$ & $<0.001$ \\
\hline Age at study inclusion (years) & $58.76 \pm 12.7$ & $52.9 \pm 11.9$ & $61.8 \pm 12.2$ & 0.003 \\
\hline Disease duration (years) & $4.6 \pm 2.3$ & $6 \pm 2.5$ & $3.9 \pm 1.8$ & 0.003 \\
\hline $\begin{array}{l}\text { Time from symptom onset to diagnosis (years) } \\
\text { Mean } \\
\text { Range }\end{array}$ & $\begin{array}{c}2.2 \pm 2.4 \\
1-11\end{array}$ & & & \\
\hline \multicolumn{5}{|l|}{ Outcome measures } \\
\hline Mean EULAR Sjogren's Syndrome Disease Activity Index & $9.95 \pm 7.73$ & $6.43 \pm 9.41$ & $11.78 \pm 6.13$ & 0.100 \\
\hline Mean EULAR Sjogren's Syndrome Patient Reported Outcome & $5.17 \pm 2.4$ & $5.095 \pm 2.700$ & $5.205 \pm 2.239$ & 0.386 \\
\hline Mean Patient Global Assessment & $5.2 \pm 2.37$ & $4.786 \pm 2.723$ & $5.423 \pm 2.176$ & 0.864 \\
\hline Mean Physician Global Assessment & $4.46 \pm 2.06$ & $3.786 \pm 2.455$ & $4.815 \pm 1.777$ & 0.879 \\
\hline \multicolumn{5}{|l|}{ Antibody profile; $n$ (\%) } \\
\hline ANA & $32(78.0)$ & $13(93)$ & $19(70)$ & 0.099 \\
\hline Anti-SSA & $19(46.3)$ & $12(86)$ & $7(26)$ & $<0.001$ \\
\hline Anti-SSB & $12(29.3)$ & $9(64)$ & $3(11)$ & $<0.001$ \\
\hline Rheumatoid factor & $10(24.4)$ & $11(79)$ & $8(30)$ & 0.168 \\
\hline Presence of extra-glandular manifestations & $36(87.8)$ & $9(64)$ & $27(100)$ & 0.001 \\
\hline
\end{tabular}

EULAR: The European League Against Rheumatism, SSA: Sjogren's syndrome A antibody, SSB: Sjogren's syndrome B antibody, 
Table 2 - Master table of all cases included in the study.

\begin{tabular}{|c|c|c|c|c|c|c|c|c|c|c|c|c|c|c|c|c|c|c|c|c|c|}
\hline Age & $\begin{array}{c}\text { Age at } \\
\text { disease } \\
\text { onset }\end{array}$ & Gender & ANA & SSA & SSB & RF & $\underset{\text { biopsy }}{\text { Lip }}$ & $\begin{array}{l}\text { Pulmo- } \\
\text { nary }\end{array}$ & Renal & $\begin{array}{l}\text { Cuta- } \\
\text { neous }\end{array}$ & Arthritis & PNS & $\begin{array}{l}\text { Cyto- } \\
\text { penia }\end{array}$ & CNS & PGA & PhGA & ESSDAI & $\begin{array}{l}\text { ESSPRI } \\
\text { for } \\
\text { dryness }\end{array}$ & $\begin{array}{l}\text { ESSPRI } \\
\text { for } \\
\text { fatigue }\end{array}$ & $\begin{array}{l}\text { ESSPRI } \\
\text { for pain }\end{array}$ & ESSPRI \\
\hline 18 & 16 & Female & 1 & 1 & 1 & 1 & 0 & 0 & 0 & 0 & 0 & 0 & 0 & 0 & 6 & 7 & 0 & 6 & 8 & 3 & 5.7 \\
\hline 34 & 29 & Female & 1 & 0 & 0 & 1 & 1 & 1 & 0 & 0 & 1 & 0 & 0 & 0 & 2 & 2 & 7 & 1 & 0 & 1 & 0.7 \\
\hline 39 & 32 & Female & 1 & 1 & 1 & 3 & 1 & 1 & 0 & 0 & 1 & 0 & 0 & 0 & 5 & 5 & 12 & 8 & 7 & 5 & 6.7 \\
\hline 43 & 37 & Female & 1 & 0 & 0 & 1 & 1 & 1 & 0 & 0 & 1 & 0 & 0 & 0 & 5 & 3 & 7 & 5 & 5 & 5 & 5 \\
\hline 43 & 40 & Female & 1 & 1 & 0 & 1 & 1 & 1 & 0 & 0 & 1 & 0 & 0 & 0 & 6 & 5 & 17 & 5 & 5 & 7 & 5.7 \\
\hline 45 & 38 & Female & 1 & 1 & 1 & 3 & 3 & 0 & 1 & 1 & 0 & 0 & 1 & 0 & 2 & 2 & 14 & 9 & 3 & 0 & 4 \\
\hline 49 & 42 & Male & 1 & 1 & 1 & 3 & 3 & 0 & 0 & 0 & 0 & 0 & 0 & 0 & 3 & 1 & 0 & 3 & 3 & 2 & 2.7 \\
\hline 50 & 46 & Female & 1 & 1 & 0 & 0 & 3 & 0 & 0 & 0 & 0 & 0 & 0 & 0 & 10 & 7 & 0 & 10 & 10 & 10 & 10 \\
\hline 50 & 47 & Female & 1 & 0 & 0 & 1 & 1 & 1 & 0 & 0 & 1 & 0 & 0 & 0 & 4 & 3 & 12 & 5 & 1 & 1 & 2.3 \\
\hline 52 & 48 & Female & 1 & 1 & 1 & 1 & 3 & 0 & 1 & 1 & 1 & 0 & 1 & 0 & 1 & 2 & 20 & 0 & 1 & 2 & 1 \\
\hline 53 & 47 & Female & 1 & 1 & 0 & 0 & 3 & 0 & 0 & 0 & 1 & 0 & 0 & 0 & 7 & 6 & 0 & 8 & 2 & 5 & 5 \\
\hline 53 & 48 & Female & 1 & 0 & 0 & 0 & 1 & 0 & 0 & 0 & 0 & 1 & 0 & 0 & 5 & 2 & 0 & 5 & 7 & 0 & 4 \\
\hline 54 & 45 & Female & 1 & 1 & 1 & 1 & 3 & 0 & 0 & 0 & 1 & 0 & 1 & 0 & 4 & 1 & 2 & 6 & 4 & 0 & 3.3 \\
\hline 54 & 46 & Female & 1 & 1 & 0 & 0 & 1 & 1 & 0 & 0 & 1 & 0 & 0 & 0 & 4 & 7 & 19 & 8 & 7 & 10 & 8.3 \\
\hline 55 & 48 & Female & 0 & 0 & 0 & 0 & 1 & 1 & 0 & 0 & 0 & 0 & 0 & 0 & 4 & 7 & 10 & 2 & 5 & 1 & 2.7 \\
\hline 55 & 50 & Female & 1 & 1 & 1 & 0 & 3 & 0 & 0 & 0 & 1 & 0 & 0 & 0 & 5 & 7 & 2 & 7 & 10 & 8 & 8.3 \\
\hline 57 & 53 & Female & 0 & 1 & 0 & 0 & 3 & 0 & 0 & 0 & 0 & 0 & 0 & 0 & 6 & 3 & 0 & 4 & 10 & 9 & 7.7 \\
\hline 57 & 53 & Female & 1 & 1 & 1 & 0 & 1 & 1 & 0 & 0 & 1 & 0 & 0 & 0 & 8 & 8 & 12 & 5 & 8 & 7 & 6.7 \\
\hline 58 & 57 & Female & 0 & 0 & 0 & 0 & 1 & 1 & 0 & 0 & 1 & 0 & 0 & 0 & 5 & 5 & 9 & 8 & 5 & 8 & 7 \\
\hline 58 & 56 & Female & 1 & 0 & 0 & 0 & 1 & 1 & 0 & 0 & 1 & 0 & 0 & 0 & 5 & 4 & 7 & 5 & 7 & 5 & 5.7 \\
\hline 60 & 55 & Female & 1 & 1 & 1 & 1 & 3 & 0 & 0 & 0 & 0 & 0 & 0 & 0 & 1 & 2 & 0 & 9 & 1 & 3 & 4.3 \\
\hline 60 & 50 & Female & 1 & 1 & 1 & 1 & 3 & 0 & 0 & 0 & 0 & 1 & 0 & 0 & 5 & 4 & 27 & 4 & 6 & 5 & 5 \\
\hline 61 & 58 & Female & 1 & 1 & 0 & 0 & 3 & 1 & 0 & 0 & 0 & 0 & 0 & 0 & 7 & 4 & 10 & 6 & 8 & 9 & 7.7 \\
\hline 61 & 59 & Female & 0 & 0 & 0 & 0 & 1 & 1 & 0 & 1 & 1 & 0 & 0 & 0 & 5 & 5 & 20 & 5 & 5 & 5 & 5 \\
\hline 61 & 57 & Female & 1 & 1 & 0 & 0 & 1 & 1 & 0 & 0 & 0 & 0 & 0 & 0 & 5 & 5 & 7 & 5 & 3 & 5 & 4.3 \\
\hline 63 & 59 & Female & 0 & 0 & 0 & 0 & 0 & 1 & 0 & 0 & 1 & 0 & 0 & 0 & 9 & 6 & 34 & 10 & 8 & 8 & 8.7 \\
\hline 64 & 61 & Female & 1 & 0 & 0 & 0 & 1 & 1 & 0 & 0 & 0 & 0 & 0 & 0 & 8 & 6 & 10 & 5 & 9 & 9 & 7.7 \\
\hline 65 & 54 & Female & 1 & 1 & 1 & 0 & 3 & 0 & 0 & 1 & 0 & 0 & 0 & 0 & 3 & 2 & 6 & 5 & 0 & 0 & 1.7 \\
\hline 66 & 65 & Male & 1 & 0 & 0 & 0 & 1 & 1 & 0 & 0 & 1 & 0 & 0 & 0 & 10 & 7 & 7 & 6 & 10 & 10 & 8.7 \\
\hline 67 & 64 & Male & 0 & 0 & 0 & 0 & 1 & 1 & 0 & 0 & 1 & 0 & 0 & 0 & 5 & 3 & 12 & 6 & 5 & 2 & 4.3 \\
\hline 69 & 64 & Female & 1 & 0 & 0 & 0 & 3 & 0 & 0 & 0 & 1 & 1 & 1 & 1 & 9 & 7 & 19 & 9 & 7 & 10 & 8.7 \\
\hline 69 & 66 & Male & 0 & 0 & 0 & 0 & 1 & 1 & 0 & 0 & 1 & 0 & 0 & 0 & 3 & 7 & 7 & 4 & 7 & 2 & 4.3 \\
\hline 70 & 66 & Male & 1 & 0 & 0 & 0 & 1 & 1 & 0 & 0 & 1 & 0 & 0 & 0 & 5 & 3 & 18 & 0 & 5 & 5 & 3.3 \\
\hline 71 & 67 & Male & 1 & 0 & 0 & 0 & 1 & 1 & 0 & 0 & 0 & 0 & 0 & 0 & 1 & 1 & 7 & 2 & 0 & 0 & 0.7 \\
\hline 71 & 68 & Male & 1 & 0 & 0 & 0 & 1 & 1 & 0 & 0 & 1 & 0 & 0 & 0 & 3 & 3 & 12 & 2 & 4 & 3 & 3 \\
\hline 71 & 70 & Male & 1 & 0 & 0 & 0 & 0 & 1 & 0 & 0 & 1 & 0 & 0 & 0 & 6 & 7 & 14 & 5 & 6 & 6 & 5.7 \\
\hline 73 & 70 & Male & 0 & 0 & 0 & 0 & 1 & 1 & 0 & 0 & 1 & 0 & 0 & 0 & 6 & 5 & 7 & 5 & 6 & 5 & 5.3 \\
\hline 75 & 73 & Female & 1 & 1 & 1 & 1 & 1 & 1 & 0 & 0 & 1 & 0 & 0 & 0 & 4 & 3 & 7 & 6 & 6 & 3 & 5 \\
\hline 75 & 74 & Female & 0 & 0 & 0 & 0 & 1 & 1 & 0 & 0 & 1 & 0 & 0 & 0 & 7 & 5 & 7 & 5 & 7 & 9 & 7 \\
\hline 77 & 73 & Female & 1 & 0 & 0 & 0 & 1 & 1 & 0 & 0 & 1 & 0 & 1 & 0 & & 5 & 18 & 2 & 3 & 3 & 3.2 \\
\hline 83 & 79 & Female & 1 & 0 & 0 & 0 & 1 & 1 & 0 & 0 & 1 & 0 & 0 & 0 & 9 & 6 & 9 & 0 & 5 & 7 & 4 \\
\hline
\end{tabular}




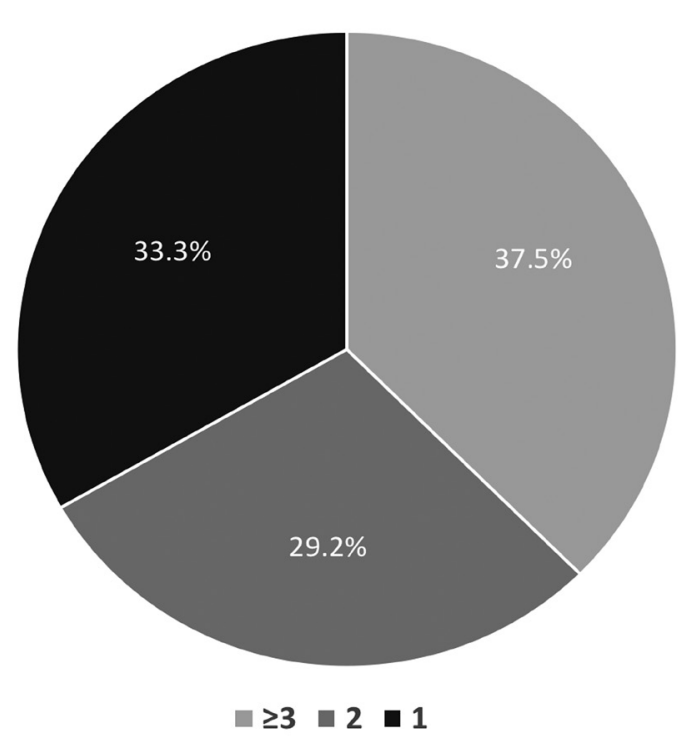

Figure 1 - Characteristics of minor salivary gland biopsy results based on the focus score $(n=24)$.

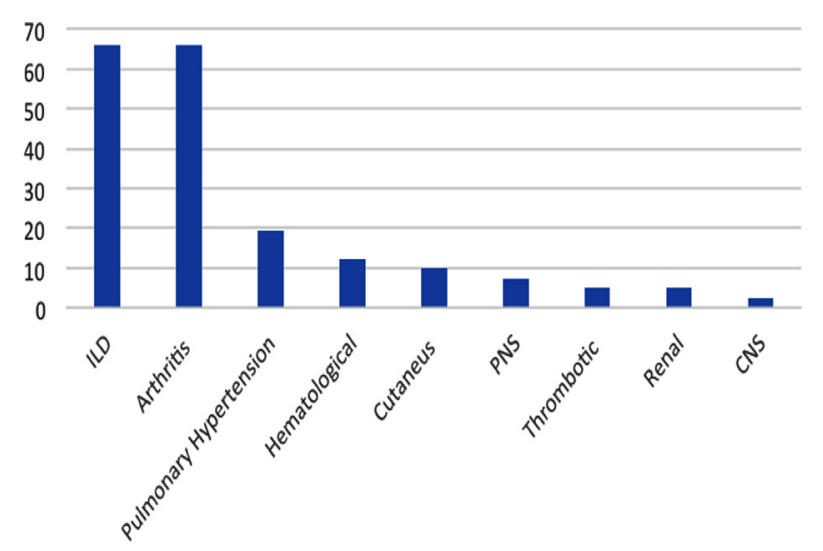

Figure 2 - Frequency of extra-glandular manifestations ( $\mathrm{n}=41)$.

clinichavedifferentmanifestation profileandbackground treatment, but no significant difference in their outcome measures.

Ethnicity plays an important role in disease phenotype of pSS in terms of patient demographics and the severity and pattern of systemic involvement, as shown in the multi-national cohort investigated by Brito-Zeron et al. ${ }^{7}$ The age at diagnosis in our patients is similar to Caucasians and older than that of Asian, Hispanic, and Black patients. ${ }^{14}$ We also observed that the rate of autoantibody positivity was similar to that in the group reported by Brito-Zeron et al and in other studies that have included ethnic minorities, including Arabs, managed by the contributing centers. ${ }^{15}$ In those studies, Black African/American patients had the highest ESSDAI scores, followed by Whites, Hispanics, and Asians, with scores ranging between 4.8 and 6.7. In our study, the mean ESSDAI was slightly higher than reported for other ethnicities. This could be explained by the high prevalence of ILD in our patients that requires confirmation in a larger more representative population. Moreover, Black/African American patients had more lymphadenopathy and articular and peripheral nervous system manifestations, whereas Caucasians had more glandular, cutaneous, and muscle tissue manifestations, Asians had more pulmonary, renal, and hematological domain involvement, and Hispanics had more constitutional domain involvement. By contrast, our Saudi patient population had more pulmonary, articular, hematological, and peripheral/central nervous system involvement, which represents a new pattern that needs to be confirmed by a larger nationwide study. Our center has reported that phenotypic characteristics of Saudi/Arab patients are different than Caucasians with lupus ${ }^{16,17}$ or spondyloarthritis. ${ }^{18}$

Despite being one of the most important challenges, diagnostic delay has not been well explored in pSS. The main factors contributing to this delay include nonspecific presenting symptoms, lack of sicca symptoms, and low sensitivity of autoantibodies. ${ }^{19}$ In a nationwide US survey, Segal et al ${ }^{20}$ described self-reported diagnostic delay in patients with confirmed pSS and US members of the Sjögren's Syndrome Foundation. The average diagnostic delay was $7.1 \pm 9.4$ years in 277 patients. ${ }^{20}$ One Ukrainian study evaluated diagnostic delay in 24 patients with pSS or secondary Sjögren's syndrome and reported a significant delay of 8.5 (range 2.8-17) years, with pSS presenting at an older age. ${ }^{21}$ The diagnostic delay in our cohort was variable, reaching 11 years in one patient; however, the mean delay was shorter than what has been reported, barely exceeding 2 years. This could be explained by 2 factors. The first is early referral to both the scleroderma spectrum disease and ILD specialized clinics. The second is rapid access to minor salivary gland biopsy within 2 weeks of referral by the oral medicine department. Measures that can facilitate early diagnosis should be a priority and can be implemented by specialties that receive patients with a suspected diagnosis of pSS, including family medicine, ophthalmologists, dentists, neurologists, and pulmonologists. The limitations of autoantibody screening should trigger use of more invasive procedures, such as minor salivary gland biopsy or measurement of salivary flow rate. Early diagnosis will help to prevent 
not only long-term local and systemic complications but also the psychological impact of the manifestations of pSS. ${ }^{22}$

Study limitations. Its small sample size, some recall bias with regard to the onset of symptoms reported by the patients, and a degree of selection bias stemming from the fact that ours is the largest center in the country receiving patients with interstitial lung disease and pulmonary hypertension. Despite its serological and clinical importance, we did not include the cryoglobulin level because it was not measured in most of the patients at the time of diagnosis and can be affected by treatment with immunosuppressive therapies.

In conclusion, this is the first report on the clinical and serological characteristics of pSS in Saudi Arabia and the Arabian Gulf region. There was a diagnostic delay of variable duration in our study participants. A national Saudi registry for pSS needs to be established in order to better understand the disease phenotype, the response to treatment, and the prognosis.

Acknowledgment. The authors would like to thank Hindawi Editing services.

\section{References}

1. Vivino FB, Bunya VY, Massaro-Giordano G, Johr CR, Giattino SL, Schorpion A, et al. Sjogren's syndrome: An update on disease pathogenesis, clinical manifestations and treatment. Clin Immunol 2019; 203: 81-121.

2. Vivino FB. Sjogren's syndrome: Clinical aspects. Clin Immunol 2017; 182: 48-54.

3. Ter Borg EJ, Kelder JC. Development of new extra-glandular manifestations or associated auto-immune diseases after establishing the diagnosis of primary Sjogren's syndrome : A long-term study of the Antonius Nieuwegein Sjogren (ANS) cohort. Rheumatol Int 2017; 37: 1153-1158.

4. Perzynska-Mazan J, Maslinska M, Gasik R. Neurological manifestations of primary Sjogren's syndrome. Reumatologia 2018; 56: 99-105.

5. Morreale M, Marchione P, Giacomini P, Pontecorvo S, Marianetti M, Vento C, et al. Neurological involvement in primary Sjogren syndrome: a focus on central nervous system. PLoS One 2014; 9: e84605.

6. Acar-Denizli N, Kostov B, Ramos-Casals M, Sjogren Big Data C. The Big Data Sjogren Consortium: a project for a new data science era. Clin Exp Rheumatol 2019; 37 Suppl 118: 19-23.

7. Brito-Zeron P, Acar-Denizli N, Ng WF, Horvath IF, Rasmussen A, Seror R, et al. Epidemiological profile and north-south gradient driving baseline systemic involvement of primary Sjogren's syndrome. Rheumatology (Oxford) 2020; 59: 2350-2359.

8. Shiboski CH, Shiboski SC, Seror R, Criswell LA, Labetoulle M, Lietman TM, et al. 2016 American College of Rheumatology/ European League Against Rheumatism classification criteria for primary Sjogren's syndrome: A consensus and data-driven methodology involving three international patient cohorts. Ann Rheum Dis 2017; 76: 9-16.
9. Seror R, Bootsma H, Saraux A, Bowman SJ, Theander E, Brun JG, et al. Defining disease activity states and clinically meaningful improvement in primary Sjogren's syndrome with EULAR primary Sjogren's syndrome disease activity (ESSDAI) and patient-reported indexes (ESSPRI). Ann Rheum Dis 2016; 75: 382-389.

10. Seror R, Bowman SJ, Brito-Zeron P, Theander E, Bootsma H, Tzioufas A, et al. EULAR Sjogren's syndrome disease activity index (ESSDAI): a user guide. RMD Open 2015; 1: e000022.

11. Seror R, Theander E, Brun JG, Ramos-Casals M, Valim V, Dorner $\mathrm{T}$, et al. Validation of EULAR primary Sjogren's syndrome disease activity (ESSDAI) and patient indexes (ESSPRI). Ann Rheum Dis 2015; 74: 859-866.

12. AlEnzi F, Alqahtani B, Alhamad EH, Daghestani M, Tashkandy Y, Othman N, et al. Fatigue in Saudi patients with primary Sjogren's syndrome and its correlation with disease characteristics and outcome measures: A cross-sectional study. Open Access Rheumatol 2020; 12: 303-308.

13. von Elm E, Altman DG, Egger M, Pocock SJ, Gotzsche PC, Vandenbroucke JP, et al. The Strengthening the Reporting of Observational Studies in Epidemiology (STROBE) statement: guidelines for reporting observational studies. J Clin Epidemiol 2008; 61: 344-349.

14. Brito-Zeron P, Acar-Denizli N, Zeher M, Rasmussen A, Seror $\mathrm{R}$, Theander $\mathrm{E}$, et al. Influence of geolocation and ethnicity on the phenotypic expression of primary Sjogren's syndrome at diagnosis in 8310 patients: a cross-sectional study from the Big Data Sjogren Project Consortium. Ann Rheum Dis 2017; 76: 1042-1050.

15. Brito-Zeron P, Acar-Denizli N, Ng WF, Zeher M, Rasmussen A, Mandl T, et al. How immunological profile drives clinical phenotype of primary Sjogren's syndrome at diagnosis: analysis of 10,500 patients (Sjogren Big Data Project). Clin Exp Rheumatol 2018; 36 Suppl 112: 102-112.

16. Al Arfaj AS, Khalil N. Clinical and immunological manifestations in 624 SLE patients in Saudi Arabia. Lupus 2009; 18: 465-473.

17. Al Arfaj AS, Khalil N, Al Saleh S. Lupus nephritis among 624 cases of systemic lupus erythematosus in Riyadh, Saudi Arabia. Rheumatol Int 2009; 29: 1057-1067.

18. Omair MA, AlDuraibi FK, Bedaiwi MK, Abdulaziz S, Husain W, El Dessougi M, et al. Prevalence of HLA-B27 in the general population and in patients with axial spondyloarthritis in Saudi Arabia. Clin Rheumatol 2017; 36: 1537-1543.

19. Martel C, Gondran G, Launay D, Lalloue F, Palat S, Lambert M, et al. Active immunological profile is associated with systemic Sjogren's syndrome. J Clin Immunol 2011; 31: 840-847.

20. Segal B, Thomas W, Rogers T, Leon JM, Hughes P, Patel D, et al. Prevalence, severity, and predictors of fatigue in subjects with primary Sjogren's syndrome. Arthritis Rheum 2008; 59: 1780-1787.

21. Kuryata O, LysunetsI T, Karavanska I, Semenov V. Duration till diagnosis and clinical profile of Sjögren's syndrome: Data from real clinical practice in a single-center cohort. The Egyptian Rheumatologist 2020; 42: 41-46.

22. Kassan SS, Moutsopoulos HM. Clinical manifestations and early diagnosis of Sjogren syndrome. Arch Intern Med 2004; 164: $1275-1284$. 